\title{
The Tendency of Diseases among Seamen during the Last Fifteen Years in Japan
}

\author{
Miho EHARA ${ }^{1 *}$, Sonoe MURAMATSU ${ }^{1}$, Yuji SANO ${ }^{1}$, Seiichi TAKEDA ${ }^{1}$ and Shuji HISAMUNE ${ }^{2}$ \\ ${ }^{1}$ Tokyo University of Marine Science and Technology, 4-5-7 Kounan, Minato-ku, Tokyo 108-8477, Japan \\ ${ }^{2}$ Hachinohe University, 13-98 Mihono, Hachinohe-shi, Aomori 031-8566, Japan
}

Received August 31, 2005 and accepted November 25, 2005

\begin{abstract}
Compared to workers on land, seamen working on the ocean are given only limited disease treatment. The aim of this paper is to clarify the actual condition of diseases among such seamen in an effort to improve measures that promote their health. We analyzed 51,641 cases of diseases that were reported to the Ministry of Land, Infrastructure and Transport from 1986 to 2000. The most prevalent diseases included disorders of the digestive system, followed by those of the musculoskeletal and the circulatory systems. The proportions of the three disease types were shown to vary by the type of work, ship, and occupation. One of the reasons for the variation in incidence between type of work and ship might result from differences in the voyage period in the given year. In explaining the varied incidences between occupations we hypothesize that differences in work systems and contents may be important variables to consider. It will be necessary to clarify the lifestyle and living environment of seamen to suggest appropriate measures for combating diseases prevalent in this population.
\end{abstract}

Key words: Health, Seamen, Disease

\section{Introduction}

Working conditions on ocean-going ships often include a labor environment that is inferior to that on land. Limited work and life space, pitching and rolling, work in 8-h shift and prolonged separation from family members during longdistance voyages characterize the hard work environment for many seamen. There is a limit to the treatment of diseases that occur on the ocean, in contrast to that of workers on land $^{11}$. Additionally the disease occurrence of one seaman may influence not only the other seamen's work but also the economic potential of the ship. These disadvantages may be similar to those in the case of trading vessels that carry shipments to their destinations by the date, as well as fishing boats that determine the extent of their profit by fish quantity and freshness.

Recently, the number of studies that evaluate seamen's diseases has decreased in Japan, and the tendency of diseases among seamen has not been clarified. Therefore, it is necessary to evaluate the actual conditions of diseases among

*To whom correspondence should be addressed. seamen in order to promote their health and reduce the disease incidence.

\section{Methods}

In addition to death, diseases and injuries among seamen that require more than three days off must be reported by ship owners to the Ministry of Land, Infrastructure and Transport in accordance with the law. In this report, the seaman is prescribed by the same law. The number of reported cases was 51,641 in the fifteen year period from 1986 to 2000. The reported diseases were classified into 18 kinds of disease codes in accordance with ICD (International statistical Classification of Diseases and Related Health Problems). ICD changed from ICD-9 to ICD-10 in 1996. So we adapted all reported diseases to ICD-10. We analyzed the disease incidence in relation to type of work, ship types and occupation types.

To obtain number of seamen in each year we referred to the Statistical Report on Seaman published by the Ministry of Land, Infrastructure and Transport. In the Statistical Report on Seamen the aggregate was made up by the scale of ship owners: one was for ship owners whose total gross tonnage 


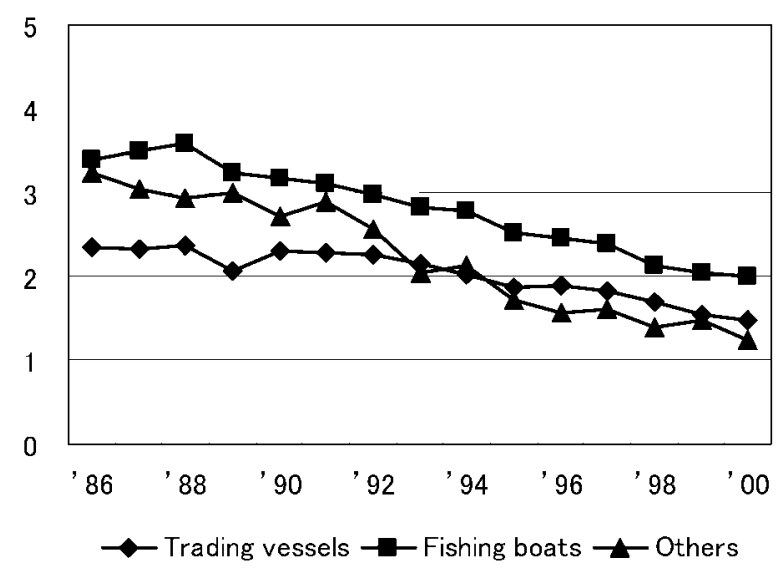

Fig. 1. Yearly change in the incidence of disease in seamen participating in three lines of work (i.e., trading vessels, fishing boats, and others) over $15 \mathrm{yr}$.

(Disease incidence per 100 seamen).

of ships was over $1,000 \mathrm{~g} / \mathrm{t}$ and another was for ship owners whose total gross tonnage was under $1,000 \mathrm{~g} / \mathrm{t}$.

\section{Results}

Fig. 1 shows the yearly change in the disease incidence in seamen engaged in three types of work (i.e., trading vessels, fishing boats and others) during the fifteen year study period. Seamen's disease rates decreased from $2.4 \%$ to $1.5 \%$ in trading vessel group, from $3.4 \%$ to $2.0 \%$ in fishing boats, and from $3.3 \%$ to $1.2 \%$ in others group. Throughout the period during which all three groups showed decline in the incidence of disease, fishing boat group held the highest incidence.

Figure 2 shows the proportions of diseases in relation to three types of work. A total of 19,088 cases were reported from trading vessels, 26,453 cases from fishing boats, and 6,100 cases from others. The reported diseases were classified into 18 kinds of disease codes in accordance with ICD (International statistical Classification of Diseases and Related Health Problems). Six kinds of diseases shown in the figure all accounted for over 5\% of total 51,641 cases. The most prevalent were diseases of the digestive system $(33.5 \%)$, followed by disorders in the musculoskeletal system $(19.6 \%)$, circulatory system $(11.6 \%)$, respiratory system $(7.7 \%)$ and neoplasm $(5.1 \%)$. These five diseases were frequent in all work type groups, and the order of incidence of these diseases was also similar. The proportions of diseases of the digestive system $(35.9 \%)$ and the musculoskeletal system $(22.6 \%)$ among seamen in fishing boat group were both higher compared with those in the groups of trading vessels and others. Conversely, the proportion of neoplasm among seamen in fishing boat group (3.8\%) was lower than

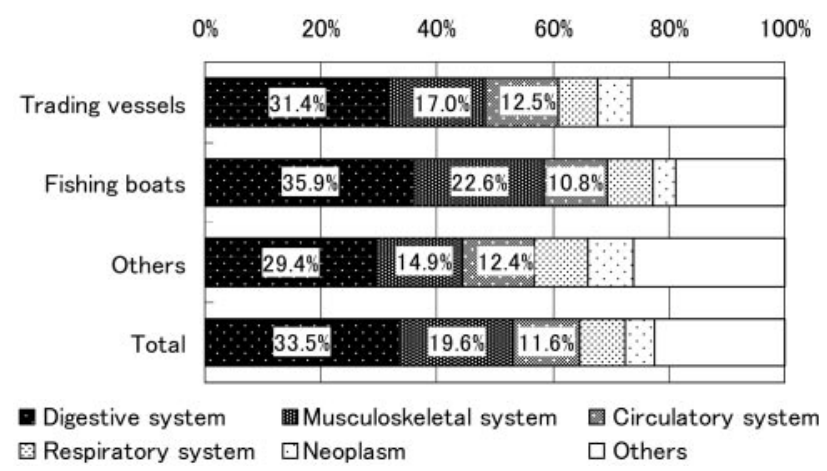

Fig. 2. Disease type in seamen performing various lines of work. It showed five prevalent diseases of seamen among 18 kinds of diseases.

those in the other two types of work.

Trading vessels are distinguished into foreign trade vessels and domestic trade vessels. The foreign trade vessel is involved in loading or unloading in the foreign port, or both. Figures 3-5 show the proportions of each disease in relation to ship types (i.e., foreign trade vessels, domestic trade vessels, and fishing boats).

As for foreign trade vessels, a total of 662 cases were reported from cargo vessels, 373 cases from oil tankers, 106 cases from LPG, 3 cases from cement carriers, 163 cases from pure car carriers, 130 cases from container carriers, 211 cases from specialized ships, 220 cases from passenger vessels and 112 cases from ferry boats. As shown in Fig. 3, the highest prevalence $(33.1 \%)$ of disorders were of the digestive system, followed by $12.8 \%$ of the musculoskeletal system, $11.8 \%$ of the circulatory system, $7.9 \%$ of the respiratory system and $2.9 \%$ of neoplasm among seamen working on foreign trade vessels.

In all categories but cement carrier the most prevalent diseases were disorders of the digestive system, with the order of the remaining diseases differing by ship type. The proportion of disorders in the digestive system varied from $21.4 \%$ in passenger vessel group to $39.8 \%$ in specialized ship group. Disorders of the musculoskeletal system-25.0\% in ferry boat group and $16.6 \%$ in pure car carrier group were high compared with other vessels. In many categories of ship the proportion of disorders in the circulatory system was more than $10 \%$. The prevalence of disorders in the respiratory system in passenger vessels was $21.4 \%$, and was higher compared with that in the vessel groups. The proportion of neoplasm was less than $6.0 \%$ in all ship types.

Regarding domestic trade vessels, a total of 4,732 cases were reported from cargo vessels, 4,416 cases from oil tankers, 608 cases from LPG, 827 cases from cement carriers, 329 cases from pure car carriers, 38 cases from container carriers, 1,501 cases from specialized ships, 939 cases from passenger vessels, 3,718 cases from ferry boats. As shown 


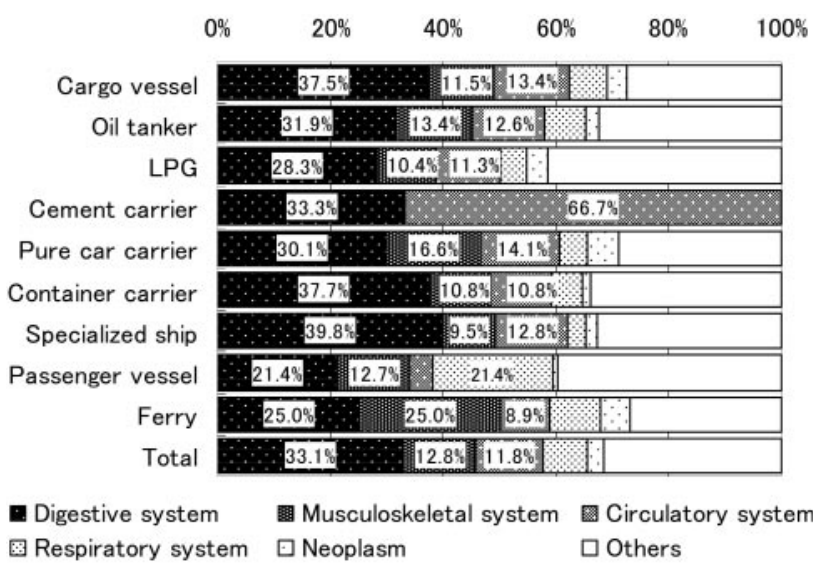

Fig. 3. Proportions of each disease in relation to ship type on foreign trade vessels.

There were nine types of ship on foreign trade vessels. It showed five prevalent diseases. It showed these in types of ship.

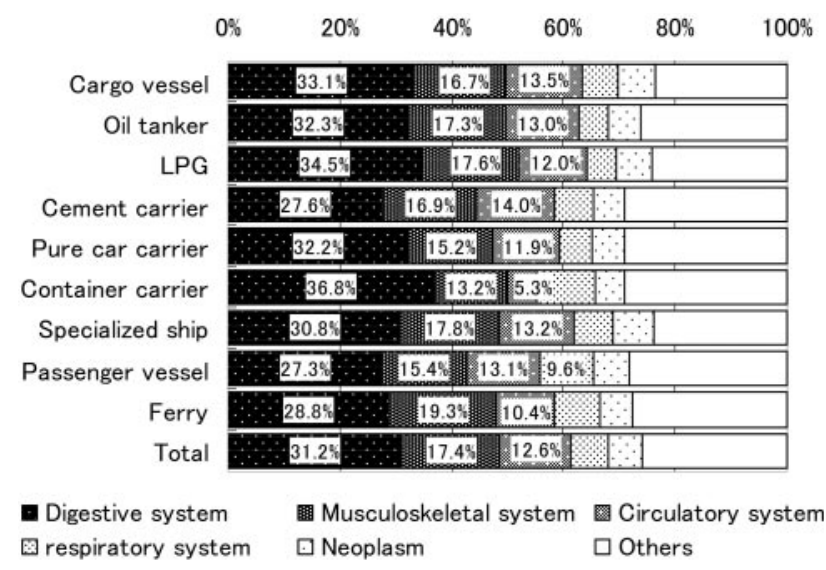

Fig. 4. Proportions of each disease in relation to ship type on domestic trade vessels.

There were nine types of ship on domestic trade vessels. It showed five prevalent diseases. It showed these in types of ship.

in Fig. 4, the most prevalent (31.2\%) were disorders in the digestive system, followed by $17.4 \%$ of the musculoskeletal system, $12.6 \%$ of the circulatory system, $6.7 \%$ of the respiratory system and $6.3 \%$ of neoplasm among seamen working on domestic trade vessels.

Except for container carriers the most prevalent disorders occurred in the following systems: 1) digestive system (approximately 30\%), 2) musculoskeletal system (15.2$19.3 \%$ ), and 3) circulatory system. Disorders of the respiratory system were higher in container and passenger vessel groups. The proportion of neoplasm was 5.3-7.3\% in all ship types. There was not much of a distinction between the disease tendencies among the ship types studied.

With regard to fishing boat type, a total of 1,912 cases

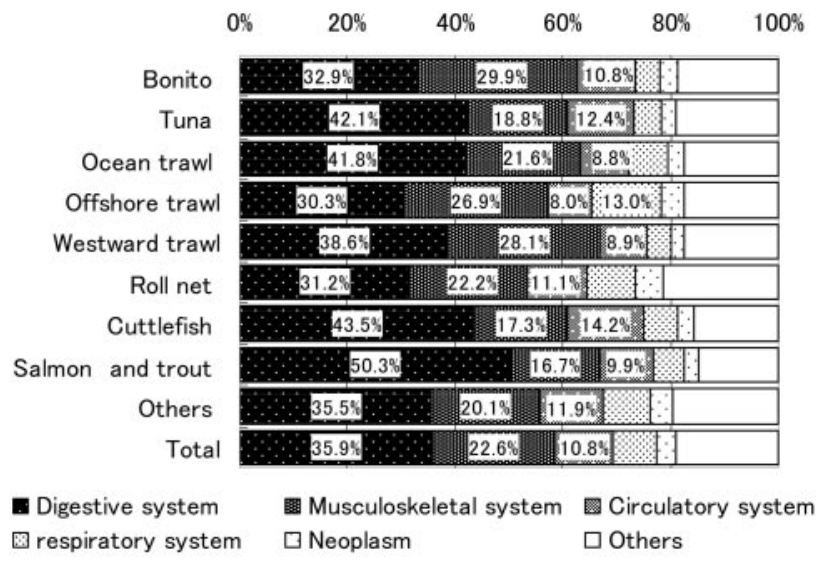

Fig. 5. Proportions of each disease in relation to ship type on fishing boats.

There were nine types of ship on fishing boats. It showed five prevalent diseases. It showed these in types of ship.

were reported from bonito, 5,294 cases from tuna, 1,382 cases from ocean trawl, 4,540 cases from offshore trawl, 1,749 cases from westward trawl, 6,254 cases from roll net, 1,615 cases from cuttlefish, 342 cases from salmon and trout, 3,365 cases from others. As shown in Fig. 5, the most prevalent disorders $(35.9 \%)$ included disorders of the digestive system, followed by $22.6 \%$ of the musculoskeletal system, $10.8 \%$ of the circulatory system, $8.0 \%$ of the respiratory system and $3.8 \%$ of neoplasm among seamen working on domestic trade vessels.

Except for the salmon and trout boat group, the most prevalent disorder was that of the digestive system (30.3$43.5 \%$ ) with the second most prevalent being disorders of the musculoskeletal system (17.3-29.9\%). The proportion of disorders in the circulatory system was high in cuttlefish vessel group (14.2\%) compared with those in other vessel groups. The disorders in the respiratory system accounted for $13.0 \%$ in offshore trawl boat group and $9.2 \%$ in roll net boat group, but in the other vessel groups these proportions were less than $10 \%$; moreover, the proportion was less than $5 \%$ in bonito and tuna vessel groups. The proportion of neoplasm was less than $5 \%$ in all ship types.

Seamen's occupations consist of officers and ratings. The proportions of each disease in relation to the two types of work in both of trading vessel and fishing boat groups were as follows.

There were a total of 10,208 officer's diseases reported in trading vessel group, which included 2,705 cases of captain, 2,714 cases of mate, 4,546 cases of engineer, 146 cases of radio operator and 97 cases of others. As shown in Fig. 6 the most prevalent $(31.8 \%)$ weredisorders in the digestive system, followed by $15.5 \%$ of the musculoskeletal system, $13.5 \%$ of the circulatory system, $6.6 \%$ of the respiratory 


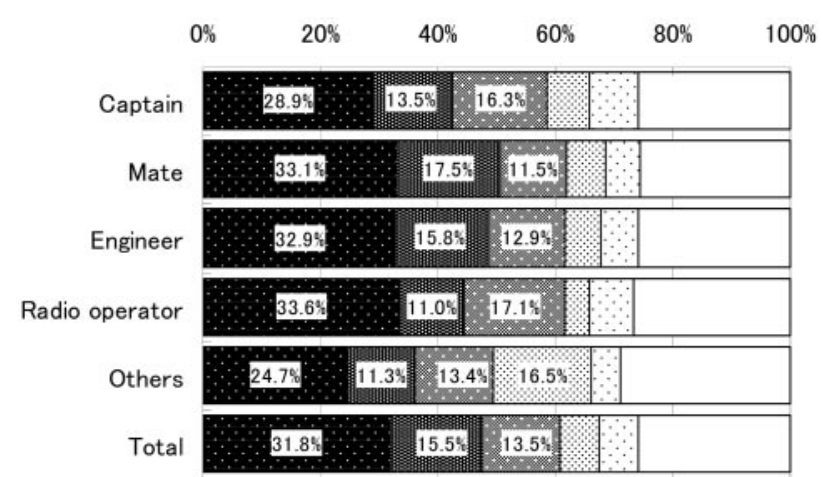

Digestive system Musculoskeletal system Girculatory system 圆 respiratory system $\square$ Neoplasm $\square$ Others

Fig. 6. Proportions of each disease in relation to occupation type among officers on trading vessels.

There were five types of occupation among officers on trading vessels. It showed these in types of their occupation.

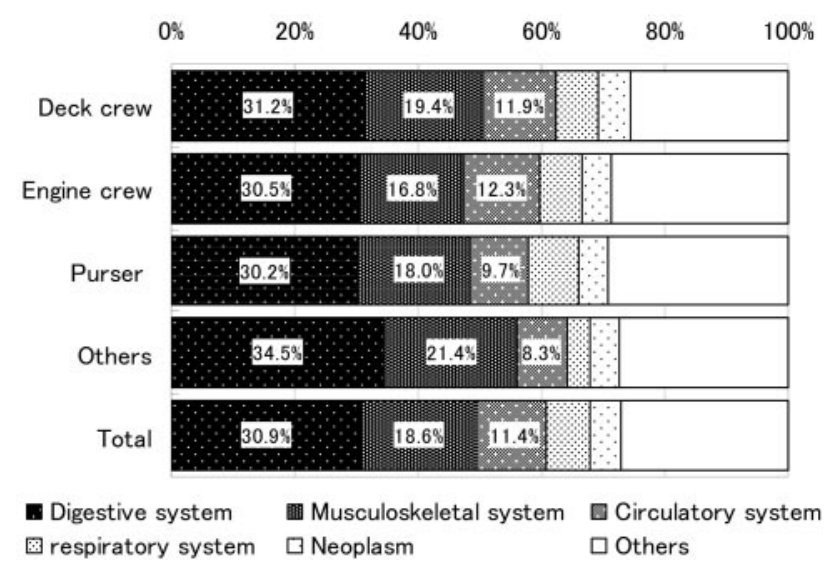

Fig. 7. Proportions of each disease in relation to occupation type among rating on trading vessels.

There were five types of occupation among ratings on trading vessels. It showed these in types of their occupation.

system and $6.7 \%$ of neoplasm among officers working on trading vessels.

Except for others group, the most prevalent disorders in all occupations were those of the digestive system (28.9$33.6 \%$ ). The proportions of disorders in the musculoskeletal system in mate group (17.5\%) and engineer group (15.8\%), were high compared with those in the other occupation groups. The disorders in the circulatory system accounted for more than $15 \%$ in captain and radio operator groups, ranking second in those two occupation groups. Except for others group, the disorders in the respiratory system made up less than $10 \%$. The proportion of neoplasm was 5.2$8.3 \%$ in all occupation groups.

There were a total of 8,880 ratings' diseases reported in

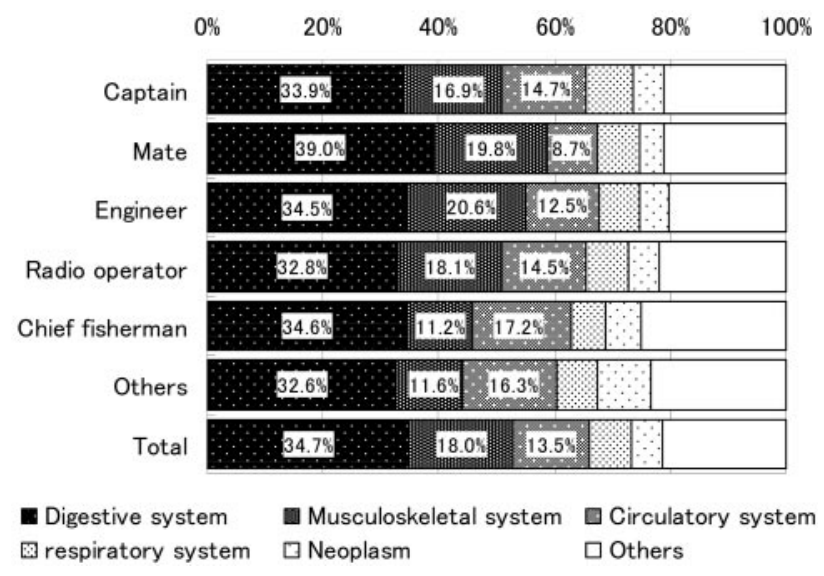

Fig. 8. Proportions of each disease in relation to occupation type among officers on fishing boats.

There were six types of occupation among officers on fishing boats. It showed these in types of their occupation.

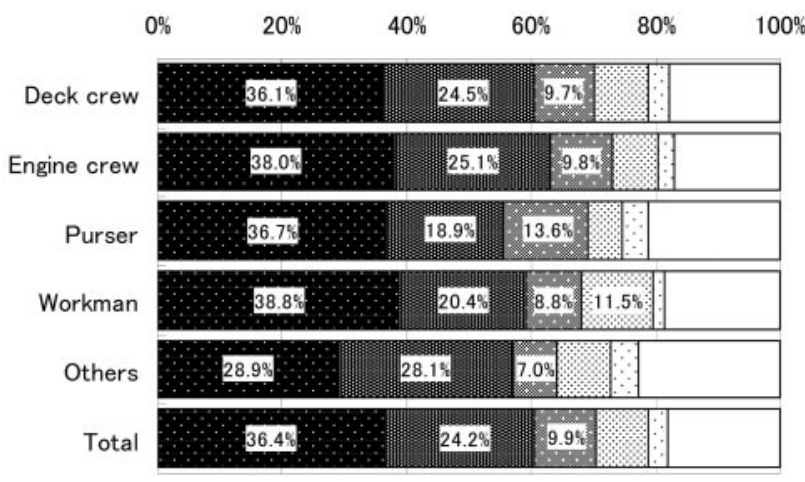

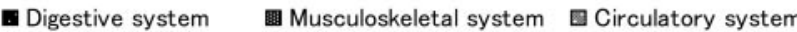
$\square$ respiratory system $\square$ Neoplasm $\square$ Others

Fig. 9. Proportions of each disease in relation to occupation type among rating on fishing boats.

There were five types of occupation among ratings on fishing boats. It showed these in types of their occupation.

trading vessel, which included 5,049 cases of deck crew, 1,542 cases of engine crew, 2,205 cases of purser and 84 cases of others. As shown in Fig. 7 the most prevalent (30.9\%) were disorders in the digestive system, followed by $18.6 \%$ of the musculoskeletal system, $11.4 \%$ of the circulatory system, $7.1 \%$ of the respiratory system and $5.0 \%$ of neoplasm among ratings working on trading vessels.

Except for others group, the disorders in the digestive system accounted for $30.2-31.2 \%$, the musculoskeletal system $16.8-19.4 \%$, the circulatory system $9.7-12.3 \%$, the respiratory system $6.8-8.0 \%$ and neoplasm $4.7-5.3 \%$. There was little difference in the proportions of these 5 diseases in each occupation group.

There were a total of 6,884 officer's diseases reported in 
fishing boat group, which included 1,806 cases of captain, 875 cases of mate, 2,438 cases of engineer, 863 cases of radio operator, 859 cases of chief fisherman and 43 cases of others. As shown in Figure 8 the most prevalent (34.7\%) were disorders in the digestive system, followed by $18.0 \%$ of the musculoskeletal system, $13.5 \%$ of the circulatory system, $7.2 \%$ of the respiratory system and $5.3 \%$ of neoplasm among officers working on fishing boats.

Prevalence of disorders in digestive system was high in mate group $(39.0 \%)$ compared with that in the other occupation groups. The proportion of the musculoskeletal system disorders in chief fisherman group (11.2\%) was smaller than those in other occupation groups (16.9-20.6\%). As for the circulatory system disorders the ratio in chief fisherman group was higher (17.2\%) compared with those in the other occupation groups $(8.7-14.7 \%)$. The proportion of respiratory system diseases was $5.7-8.0 \%$ and that of neoplasm was $4.1-6.4 \%$.

There were a total of 19,569 ratings' diseases reported in fishing boats, which included 15,080 cases of deck crew, 2,890 cases of engine crew, 1,225 cases of purser, 260 cases of workman and 114 cases of others. As shown in Figure 9 the most prevalent $(36.4 \%)$ were disorders in the digestive system, followed by $24.2 \%$ of the musculoskeletal system, $9.9 \%$ of the circulatory system, $8.2 \%$ of the respiratory system and $3.3 \%$ of neoplasm among ratings working on fishing boats.

In all occupations the total of the proportion of these top 2 diseases was approximately $60 \%$. The proportion of diseases of the circulatory system was $13.6 \%$ in purser group, being higher than those in the other occupation groups. Proportions of the disorders of the respiratory system were different among occupation groups (5.5-11.5\%). Neoplasm made up less than $5 \%$ in all occupation groups.

\section{Discussion}

As the first step to take appropriate measures for promoting seamen's health and decreasing their disease, we analyzed the seamen's disease data reported to the Ministry of Land, Infrastructure and Transport during a fifteen-year period. The seamen's disease incidence decreased in any work type group, but it remained high in fishing boat group through out the period.

According to the Statistical Report on Seaman, seamen in their thirties and forties accounted for more than $30 \%$ of all working on both trading vessels and fishing boats in $1986^{2}$. However, among worker on trading vessels seamen in their forties and fifties accounted more than $30 \%$ in $2000^{3}$. On the other hand, in the case of fishing boats seamen in their twenties and fifties each accounted for approximately one quarter of those working on such vessels. Although the proportion of the advanced age groups was higher in trading vessel group compared with that in fishing boat group in recent years, the disease incidence in seamen working on fishing boats was higher than that on trading vessels. In order to know the reason for this high incidence of fishing boats it is necessary to clarify the actual life styles and living environments of seamen.

Among the diseases of seamen, the most prevalent were disorders in the digestive system followed by those of the musculoskeletal system, the circulatory system, the respiratory system and neoplasm in any type of work. The total proportion of these diseases was approximately 70 $80 \%$. The proportions of disorders in the digestive system and the musculoskeletal system were higher in fishing boat group compared with those in the groups of trading vessels and others.

To reduce the incidence of seamen's diseases it is important to make measuresments of these five diseases, especially disorders in the digestive system, the musculoskeletal system and circulatory system, which exhibited high proportions. Disorders in the digestive system and circulatory system might be related to lifestyle, especially smoking and drinking, and the disorders in the musculoskeletal system might be related to posture during work.

Regarding foreign trade vessels, of all ship types but cement carrier the most prevalent were disorders of the digestive system, and the rank order of the remaining diseases was different among them. The proportions of each disease differed among ship types. Among domestic trade vessels except for container carriers the most prevalent was also disorders in the digestive system; the next was the musculoskeletal system and the circulatory system. There was not much difference among ship types. In the fishing boat group the most prevalent were also disorders in the digestive system, followed by those of the musculoskeletal system in all type of ships. The proportions of these diseases differd among ship types.

Among trading vessels the distribution of seamen's diseases was different between foreign and domestic ships. One of the reasons might be related to differences in the voyage period. The domestic trade vessels navigate between ports in Japan, with periods of less than $120 \mathrm{~d}$ a year accounting for about $70 \%$ of the voyages. On the other hand, foreign trade vessels navigate on the open sea, and periods of less than $120 \mathrm{~d}$ a year accounting for only $20 \%$ of the voyages. Therefore, among the foreign trade vessels voyage periods were longer and the period varied by type of ship ${ }^{4}$. In fishing boats this variation of voyage period also exists and varied by type of boat $t^{5)}$.

In both group of trading vessels and fishing boats, the incidence of the disorders in the circulatory system was higher among officers; among ratings that of the disorders of the musculoskeletal system was higher compared with among officers. There was not much difference between occupations 
in ratings in both work types. In trading vessel group the incidence of the disorders in the musculoskeletal system was high in mates and in engineers, and that of the circulatory system disorders was high in captains and radio operators among officers. There was little difference in the incidence made by occupation types among ratings. In fishing boat group the disorders in the digestive system were prevalent in mates, the circulatory system disorders were prevalent in chief fishermen among officers. There was also little difference in the incidence between occupation types, with the exception of pursers among ratings.

In an effort to determine the reasons for the differences in proportions among occupation groups, we considered seamens' work systems and contents. Almost all seamen work in $8 \mathrm{~h}$ shift: four hours in watch keeping and eighthour rest, or $6 \mathrm{~h}$ shift: six hours in watch keeping and rest. An exception is the captain seamen who don't have watch keeping and are normally engaged in daywork ${ }^{6,7)}$. On trading vessels the captain has to be awake to work, and deal with whatever happens during the night ${ }^{8}$. It is expected that the captain should shoulder physical burdens in addition to the mental burden involved in assuring a safe voyage. Similarly, the chief fisherman takes full responsibility for total management of fishing. The catch of fish depends on his discretion ${ }^{9)}$, so it is easily expected that he is under pressure through out the period of voyage, often with insufficient time to rest.

The Ministry of Health, Labour and Welfare investigates the number of patients for a year. Although some conditions are different from those of seamen, among outpatients the most prevalent disorder was also that in the digestive system (18.9\%), followed by the musculoskeletal system (14.8\%) and the circulatory system (13.0\%) in $2001^{10)}$. However, the proportion of disorders of the digestive system and the musculoskeletal system among seamen was higher than that among the above mentioned out patients.

The national wide activity to promote health is performed by Ministry of Health, Labour and Welfare ${ }^{11)}$, but it might be difficult to do the same for seamen. A limited ability to intercede in their lives, as a result of their living environment, limited of time, space, meals, and more, makes it important to exchange information about diseases and countermeasures not only with medical facilities but also seamen.

\section{Acknowledgements}

This paper owes much to the thoughtful and helpful comments of Mr. Masataka Shoda, Yokohama Seamen's Insurance Hospital and Mr. Kenji Takahashi, All Japan Seamen's Union.

\section{References}

1) Shinoda $R$ (1967) Introduction of Marine Medicine. Maritime Medicine 26, 4-32.

2) Ministry of Land, Infrastructure and Transport (1986) The Statistical Report on Seamen. Available at http:// toukei.mlit.go.jp/search/pdf/02/02198600ab0000.pdf (in Japanese) (Accessed May 1, 2005).

3) Ministry of Land, Infrastructure and Transport (2000) The Statistical Report on Seamen. Available at http:// toukei.mlit.go.jp/search/pdf/02/02200000ab0000.pdf (in Japanese) (Accessed May 1, 2005).

4) Kato K, Hisamune S (2000) Mental Health, Life Style, and Work Environment Among Seamen ('99 1st Report) Maritime Labor Research Institute, Tokyo (in Japanese).

5) The Mercantile Marine Institute of Japan (1984) Consciousness of living and work among seamen working in deep sea fisheries. The Mercantile Marine Institute of Japan, Tokyo (in Japanese, title tentatively translated).

6) Colquhoun WP, Watson KJ and Gordon DS (1987) A shipboard study of a four-crew rotating watchkeeping system. Ergonomics 30, 1341-52.

7) Colquhoun WP, Rutenfranz J, Goethe H, Neidhart B, Condon R, Plett R, Knauth P (1988) Work at sea: a study of sleep, and of circadian rhythms in physiological and psychological functions, in watchkeepers on merchant vessels. I. Watchkeeping on board ships: a methodological approach. Int Arch Occup Environ Health 60, 321-9.

8) Kato K, Hisamune S (2001) Mental Health, Life Style, and Work Environment Among Seamen (2001 Final Report) Maritime Labor Research Institute, Tokyo (in Japanese).

9) Miwa C (2000) The present argument about labor on fishing industry. Seizandoshoten, Tokyo (in Japanese, title tentatively translated).

10) Ministry of Health and Welfare, Minister's Secretariat, Statistics and Information Department (2002) Healthcare statistics in Japan 17. Health and Welfare Statistics Association, Tokyo (in Japanese).

11) Tatara K (2001) Guideline for propulsion of "Healthy Japan 21'. 97-368, Gyousei, Tokyo (in Japanese, title tentatively translated). 